\title{
Adapting Evidence-Based Interventions to Meet the Needs of Adolescents Growing Up with HIV in South Africa: The VUKA Case Example
}

\author{
Claude Ann Mellins • Danielle Nestadt • Arvin Bhana • Inge Petersen • \\ Elaine J. Abrams • Stacey Alicea • Helga Holst • Nonhlahla Myeza • Sally John • \\ Latoya Small • Mary McKay
}

Published online: 16 August 2014

(C) Springer International Publishing 2014

\begin{abstract}
The VUKA family program is one of the only evidence-based interventions to promote positive psychosocial outcomes in South African HIV-infected pre- and early adolescents and their families. In this paper, we discuss the collaborative process by which a multidisciplinary team of clinicians, researchers, counselors, and artists/educators and families adapted and developed VUKA for this population using community-based participatory research methods. We describe the intervention and explore lessons learned that may
\end{abstract}

C. A. Mellins $(\triangle) \cdot$ D. Nestadt

HIV Center for Clinical and Behavioral Studies, New York State Psychiatric Institute and Columbia University, New York, NY, USA e-mail: cam14@columbia.edu

A. Bhana $\cdot$ I. Petersen

School of Applied Human Sciences, University of KwaZulu-Natal, Durban, South Africa

E. J. Abrams

ICAP at Columbia University, Mailman School of Public Health, New York, Columbia University, New York, NY, USA

\section{E. J. Abrams}

Department of Pediatrics, College of Physicians \& Surgeons, Columbia University, New York, NY, USA

\section{S. Alicea}

Department of Applied Psychology, New York University, New

York, NY, USA

H. Holst $\cdot$ S. John

McCord Hospital, Durban, South Africa

N. Myeza

Private Practice, UKZN, Durban, South Africa

L. Small $\cdot$ M. McKay

McSilver Institute for Poverty Policy and Research, Silver School of Social Work, New York University, New York, NY, USA be applicable across contexts related to international collaboration and adapting evidence-based interventions so that they are likely to be acceptable, feasible, and effective in a given setting and country context.

Keywords Adolescents · Pediatric HIV · Mental health · Adherence · Family intervention development

Adolescence is an age of opportunity for children, and a pivotal time for us to build on their development..... to help them navigate risks and vulnerabilities, and to set them on the path to fulfilling their potential

UNICEF (2011) Opportunity in Crisis

The global pediatric HIV epidemic in countries with longstanding access to antiretroviral treatment (ART) and significant health care resources is predominantly an adolescent and young adult epidemic. This is primarily due to two factors: (a) few new cases of pediatric HIV due to successful efforts to identify and treat HIV+ pregnant women in order to protect their health and prevent perinatal HIV transmission and (b) highly potent treatments that have prolonged the lives of those children who acquired perinatal HIV infection (Abrams et al. 2001; Connor et al. 1994; Coovadia et al. 2012; de Martino et al. 2000; Department of Health \& Human Services 2014; Sohn \& Hazra 2013; UNAIDS 2012). For example, in the USA, less than 1-2 \% of babies born to HIV-infected mothers actually acquire the virus, and the vast majority of children born with HIV are now 13 years and older (Centers for Disease Control \& Prevention 2013; New York City Department of Health 2012).

Unfortunately, in many countries with more limited resources, these prevention and treatment efforts came late and/or have been slow to scale up, leading to staggering rates of HIV infection in women and hundreds of thousands of babies born with HIV. UNAIDS (2012) estimates there are 
3.3 million children under 15 years of age with HIV across the globe; the vast majority with perinatal HIV infection are in sub-Saharan Africa. With renewed global efforts to make ART universally available, it is likely that more children will access treatment and reach adolescence, a time of tremendous physical, cognitive, and emotional growth, as well as a time of increased risk behavior that can be a barrier to successful development (Domek 2006; Hamburg 1990; Sohn \& Hazra 2013). Although an increasing literature indicates significant risk for poor behavioral outcomes that affect health and development in adolescents who have grown up with HIV, to date, few evidence-based behavioral interventions exist to promote well-being and resilience in this population (Betancourt et al. 2013; Domek 2009; Mellins \& Malee 2013).

\section{Why Are Perinatally HIV-Infected (PHIV+) Youth at Risk for Poor Health and Behavioral Outcomes?}

Globally, they are most often made vulnerable by poverty with limited access to health care and educational resources (UNAIDS, UNICEF, \& USAID 2004). They have experienced disruptions in caregiving due to a variety of factors, including parental illness and death, leading to emotional and behavioral problems as youth struggle to overcome the disruptions in their lives (Cluver et al. 2011; Kang et al. 2008). In some countries, parental substance abuse and untreated mental illness have decimated families, and youth are often at greater genetic and environmental risk for mental health and substance abuse problems of their own (Gadow et al. 2012; Havens \& Mellins 2008). Also, in many countries, PHIV+ youth are born into families who have experienced severe discrimination and now must cope with the added burden of HIV-related stigma (Boyd-Franklin et al. 1995; Cluver et al. 2008; Mellins \& Malee 2013; Nyblade et al. 2009, 2011).

Moreover, in many global contexts, children who were born either before the widespread use of combination ART (cART), or who were not identified as HIV-infected until late childhood/early adolescence, were typically exposed to many years of sustained viral replication (Ferrand et al. 2007; Meyers et al. 2007; Sohn \& Hazra 2013; Van Dyke et al. 2011). In addition to its health ramifications, HIV can have a destructive effect on the central nervous system, with significant neuro-developmental and cognitive deficits that impact development, including critical domains of childhood and adolescence, such as school achievement, peer relationships, emotional functioning, and problem-solving skills around experimentation with alcohol and drugs, as well as sexuality and transition to independence (Brouwers et al. 1991; Chase et al. 2000; Smith \& Wilkins 2014; Wiener \& Mellins 2012).

Cohort studies from the USA have found high rates of behavioral health problems in PHIV+ youth, particularly mental health problems (Gadow et al. 2012; Malee et al. 2011;
Mellins \& Malee 2013; Mellin et al. 2012), as have several international studies (Bomba et al. 2010; Menon et al. 2007; Puthanakit et al. 2013), and studies from across the globe are now documenting that, like other youth their age, PHIV+ youth are experimenting with substances and sexual behavior and are inconsistent in condom use (Bauermeister et al. 2012; Mellins et al. 2011; Tassiopoulos et al. 2013). Moreover, an alarming number of studies of PHIV+ youth have documented high rates of non-adherence to ART that can lead to very poor health outcomes and increased risk of HIV transmission to others. One study has also shown that adolescents with perinatal HIV have higher rates of ART resistance and lower rates of viral suppression than adult populations (Van Dyke et al. 2014; Tassiopoulos et al. 2013). To date, the majority of interventions for PHIV + youth are focused on biomedical outcomes. However, as has been noted in other populations of vulnerable youth, failure to address their psychosocial needs and behavioral outcomes may lead to costly, long-term individual health and public health consequences (e.g., Domek 2006, 2009; Mellins \& Malee 2013; Williamson 2005).

\section{South Africa HIV Epidemic}

South Africa has one of the highest HIV seroprevalence rates in the world with nearly $40 \%$ of women in antenatal clinics in some parts of the country, including KwaZulu-Natal testing positive for HIV (UNAIDS 2010). An estimated 334,000 children are living with HIV in South Africa and were primarily infected perinatally (Republic of South Africa 2010). Significant numbers of these youth are growing up in poverty and have experienced considerable discrimination and family disruption due in part to the legacy of Apartheid. As noted, few evidence-based, behaviorally focused programs have addressed HIV+ adolescents' specific mental health and behavioral health prevention needs (King et al. 2009; Mellins \& Malee 2013). Thus, there is an urgent need for interventions to help these young people in this context to achieve health-promoting behaviors. Because considerable evidence suggests that risk prevention is much easier than treatment of the consequences of risk behaviors that have already occurred, interventions that target youth before they are engaged in risk behaviors, such as pre- and early adolescence, may be most effective.

\section{CHAMP+}

CHAMP+, based on the "Collaborative HIV Prevention and Adolescent Mental Health Program (CHAMP)," is one of the very few interventions developed for PHIV+ pre- and early adolescents that are being tested in randomized controlled trials (RCTs) (McKay et al. 2014; McKay \& Paikoff 2007). CHAMP is a developmentally timed, multi-session, multiple family group 
intervention that targets families with pre- and early adolescents to promote mental health and prevent sexual and drug risk behaviors before problems emerge. It was originally developed for uninfected youth in Chicago by clinicians and researchers working with communities to target multiple systems.

Multiple families come together for an average of 10 sessions focused on communication within families, HIV knowledge, parental supervision and monitoring, puberty, social support, and navigating risky situations, with both separate and combined caregiver and youth groups. It was tested and validated in multiple RCTs in Chicago and New York City, and subsequently adapted and tested with uninfected youth in South Africa (CHAMPSA), as well as several other countries (Bell et al. 2008; Bhana et al.; 2010). Data from the various trials have consistently shown improved family process variables (i.e., communication, parent-child involvement, supervision, support) and youth mental health, self-esteem, and peer negotiation skills, as well as reduced youth participation in situations of sexual and drug use possibility (Bhana et al. 2010; McKay \& Paikoff 2007).

CHAMP + was originally developed for PHIV + youth in New York, USA (McKay et al. 2007a, 2014) after clinical requests from providers, caregivers, and PHIV+ youth for assistance around prevention of HIV transmission risk behaviors and promotion of ART adherence were made to several of the investigators. The content of the program was created via intensive community-based participatory research (CBPR) methods, with multiple collaborative pilot tests conducted to enhance the likelihood of relevance, feasibility, and ultimately impact (see McKay et al. 2007b for details).

Similar to the New York experience, members of the investigative team were approached by clinicians and stakeholders in South Africa to develop HIV prevention and adherence promotion interventions for the growing population of PHIV+ youth. Although the pilot of CHAMP+ in the USA proved promising, prior to implementing interventions tested in the USA or elsewhere in another country, there is a need to determine the fit of the intervention for the local context, preferably through collaborations between prevention scientists and people with first-hand knowledge of the local cultural and psychosocial environment, as well as formative research to understand the needs and socio-cultural circumstances of the targeted group (Corby 1997; Wainberg et al. 2007).

Using CBPR, this process of intervention adaptation involves balancing the need to optimize fit to local context with fidelity to key components of the tested intervention, followed by pilot testing and further refining the intervention (Wainberg et al. 2007). This article describes the development/adaptation of a family-based HIV prevention and mental health promotion program, originally developed for PHIV+ pre- and early adolescents and their families in the USA, for PHIV+ South African adolescents and their caregivers. Originally called CHAMP $+\mathrm{SA}$, the intervention was renamed VUKA by
South African stakeholders ("Wake up" in isiZulu). External research funding support was obtained from the National Institute of Nursing Research to conduct a pilot study guided by three aims: (1) to identify key psychosocial, health, and behavioral issues for PHIV+ youth and their families, (2) to develop/adapt CHAMP+ for the South African context using CBPR and multidisciplinary work groups to review the findings related to aim 1 and previous versions of CHAMP and CHAMP+, and (3) to conduct a pilot test of the intervention with 65 families randomized to receive VUKA or standard of care. Findings from aim 1 and aim 3 have been published previously (Bhana et al. 2014; Petersen et al. 2010) and the results of the pilot trial were promising. Briefly, despite the relatively small sample size of the pilot, comparisons between VUKA and the comparison group arms revealed some significant differences and trends on key domains, including ART adherence, HIV treatment knowledge, and caregiver-child communication and participants in the VUKA arm evidenced improvement in all key outcomes, including mental health, youth behavior, HIV treatment knowledge, stigma, communication, and adherence to medication. Moreover, there was high acceptability and feasibility. Among the 33 families randomized to the VUKA arm, 32 attended at least one session, $100 \%$ of whom completed the trial, with $94 \%$ attending at least 5 of the 6 days. Thus VUKA, similar to the US trial of CHAMP+ shows promise as a family-based mental health and HIV prevention program for HIV pre- and early adolescents.

That said, neither of the previous publications focused on the process by which VUKA was created. This paper focuses on aim 2 , specifying the process by which a multidisciplinary team of physicians, nurses, psychologists, social workers, lay counselors, and researchers, came together with HIV+ youth, family members, South African artists, and educators/ curriculum developers, using international collaboration and CBPR methods, to create a psychosocial support and behaviorally focused intervention that could be implemented by lay counselors and that would be accessible, acceptable, and effective with PHIV+ youth and their families living in South Africa. Describing this process of intervention development is often left out of published work, and guidelines for helping providers adapt evidence-based programs for different contexts are lacking. Yet, this information may be critical to helping providers across the globe adapt interventions that can be easily disseminated in their context.

\section{Methods}

Study Location and Participants

The VUKA project took place in a private hospital in Durban, South Africa. This hospital had a very early commitment to 
providing cART to PHIV+ children, prior to the roll out in South Africa. Further, the treatment model adopted by this particular hospital endorsed comprehensive, family-based care, including psychosocial counseling and support services. The hospital had one of the largest pediatric, as well as adult, HIV/AIDS clinics in Durban at the time of this study with 3,649 adults and 665 children receiving ART at the end of 2010. Thus, the hospital director and clinic providers were motivated to participate in the development and testing of VUKA as they were unaware of any existing evidencebased interventions to promote behavioral health outcomes for their rapidly growing population of PHIV+ children. After hearing the lead author present data on the behavioral health needs of PHIV + youth, the CEO of the hospital and the head of the HIV medical clinic requested help with behavioral programming.

Participants for this study included PHIV+ adolescent patients receiving HIV care at the hospital and their caregivers (birth parents, relatives, and adoptive parents), as well as health care providers from the hospital's HIV clinic. Youth and their caregivers were almost exclusively Black South Africans and Zulu-speaking, living in townships near Durban where the hospital was located. While youth were evenly distributed by gender, caregivers were predominantly women, reflecting the family situations of the youth.

Provider consultants who worked with HIV+ adolescents were identified by hospital administrators and referred to the project director for this study. Providers were of mixed race/ethnicity and gender and included physicians, nurses, psychologists, social workers, and lay HIV treatment counselors. The director of the HIV medical clinic and the CEO of the hospital participated in some of the sessions, as well. Providers were not reimbursed for their time and no identifying data was collected from them. Their participation was considered part of the intervention development activities. Food was served at all workshop meetings.

Phase I: Intervention Adaptation Participants and Procedures

As noted, a key component of adapting the CHAMP program of interventions for new settings and populations is the involvement of consumers and stakeholders to increase the acceptability, efficacy, cultural and contextual sensitivity, and sense of ownership by local stakeholders, as well as capacity for wider scale use. Figure 1 (Mellins 2012) presents a heuristic of the area of expertise, content, and specific types of people who contributed to the creation of VUKA, which ultimately was designed to target multiple behavioral domains of youth outcomes for South African PHIV+ youth.

For phase 1, purposive sampling was used to identify and recruit consumer consultants (HIV+ youth and their families).
Youth had to know their diagnosis so that HIV could be discussed and were 14 to 16 years of age so that they could offer retrospective insight into the needs of early adolescents. Caregiver consultants had to be caring for an HIV + adolescent (ages 9-14 years). Adult caregiver consultants all provided written consent; youth consultants provided written assent and needed caregiver written consent to be in the study. All were reimbursed the equivalent of about US $\$ 10$ for their participation time and travel. All procedures received institutional review board approval by US and South African institutions of the investigators, including the hospital (see Petersen et al. 2010).

Phase 1, Part 1 Procedures The first step in the adaptation was to conduct qualitative individual interviews with the youth and caregiver consumer consultants in order to understand key psychosocial challenges and protective influences for HIV+ youth and their caregivers. Special attention was given to South African family life and parenting, the language used to discuss HIV, mental health issues, and risk behavior, parent-child communication, coping strategies in response to HIV, stressful life events, beliefs about professionally driven interventions (e.g., stigma, trust), the role of psychosocial issues in pediatric HIV care, and the ways in which a child's health prognosis or caregiver HIV status affects communication and parenting in South Africa. Twenty-five HIV+ adolescents and 15 caregivers participated. Interviews were tape recorded in isiZulu and translated and transcribed into English, with back-translation checks by an independent, bilingual English-isiZulu speaker. The data were analyzed by several of the authors using thematic analysis; data across focus groups and individual interviews were read twice to identify common issues or constructs that were grouped into common themes and used to form a coding framework. The data were then coded according to these common themes by two independent coders using NVivo 8 software (QSR International) to verify and ensure reliability of the emergent themes (procedures described fully in Petersen et al. 2010).

Phase 1, Part 2 Procedures In the second step, workgroups were conducted with (a) ten consumer consultants (five caregivers and five HIV+ adolescents); (b) ten providers, including physicians, nurses, psychological counselors, and HIV lay counselors; and (c) one to three of the study investigators to develop the VUKA program. The consumers participated in four meetings, some with youth and caregivers together, and some separate.

In the first few meetings, participants were shown relevant parts of several different CHAMP curricula (CHAMP, CHAMPSA, CHAMP+US) and were asked to provide feedback on the relevance of the content to their lives and 
Fig. 1 Collaborators on VUKA

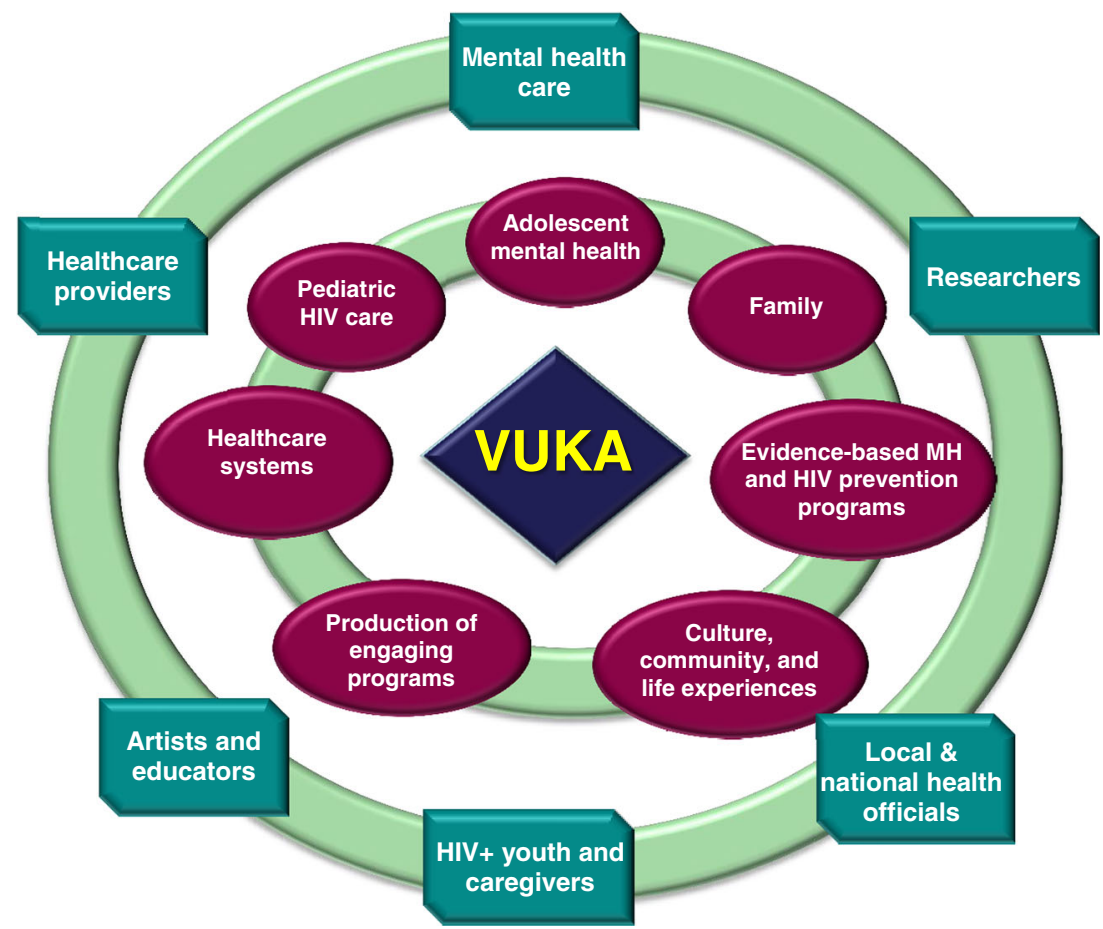

the challenges they faced. Further, the findings of the qualitative interviews were shared with consultants for follow-up discussion and informed the ultimate content of the VUKA curriculum. Consumer consultants also provided session-bysession feedback on the CHAMP+US and CHAMPSA curricula and commented on difficulties in situating this type of intervention within the routines of South African family life and health care. They were asked to consider how the issues raised by the group could be incorporated into the program and examine the appropriateness of existing study procedures, including the use of multiple family group meetings (see "Results").

Four provider consultant groups were also held, some jointly with consumers. Provider sessions examined factors related to feasibility and acceptance of intervention goals, as well as the mental health and behavioral outcomes (adherence to ART, sexual risk behavior), and barriers related to staff time, space constraints, scheduling, and stigma regarding psychosocial interventions. These sessions also addressed critical issues for HIV-affected families, barriers to psychosocial interventions at the hospital, and the appropriateness of our study protocol, particularly regarding procedures for recruitment, confidentiality, and local approaches to working with patients and delivering interventions.

Providers also discussed the roles of different health care and psychosocial staff, including nurses, HIV counselors, and psychology trainees, in addressing behavioral issues such as adherence, sexual risk, and disclosure. This was particularly important given the large numbers of HIV+ patients at the hospital and limited resources for professional staff, particularly for behavioral interventions. As in other types of clinics in low resource settings, some of the psychosocial support interventions, particularly around HIV testing, are administered by lay counselors under the supervision of professional providers such as nurses, social workers, and psychologists. Thus, part of the goal of the sessions was to identify existing resources to make the VUKA intervention feasible, as well as effective, and sustainable in this setting.

Note that although not initially planned, early on in the process in meeting with providers, it became clear that the cartoon-based curriculum format of CHAMPSA (see "Results" section for description) was much preferred to the written materials of the original CHAMP and CHAMP+US. As a result, the artists/educator team who had created CHAMPSA were brought in to attend these meetings and to engage with the stakeholders and investigators in an iterative process involving sketches, character development, story lines, and story-boards.

Each of the consultant groups was facilitated by the project director and usually one of the investigators trained in CHAMP and group facilitation. The project director took field notes, documenting the emerging issues, as well as the processes by which decisions were made. The facilitators provided a report each week summarizing the points covered and the significant issues that emerged. These field notes and reports were used to guide the intervention development and to have a record of decision making throughout. In total, phase 1 of this project took 1 year to complete. 


\section{Results}

Phase 1, Part 1: Focus Groups and Qualitative Interviews with Stakeholders

Extensive descriptions of the data from this phase have been published (Petersen et al. 2010) and are presented briefly here as the data informed the workgroup activities in part 2. In brief, participants discussed the importance of multiple family members in raising children, the limited discussions of HIV, their concerns about sexual and drug risk behavior, and caregiver-youth difficulties with talking about HIV and loss. Psychosocial problems and challenges that emerged from patients and caregivers included unfulfilled bereaving at the loss of biological parents, difficulty accepting and dealing with identity, and status issues related to living with HIV, high external stigma, and discrimination that lead to difficulties with disclosure to other family members, friends, and peers, and difficulties in understanding ART and adherence (Mellins et al. 2012; Petersen et al. 2010). These themes were presented to the workgroups in the next phase to consider ways of incorporating them into the revised protocol.

\section{Phase 1, Part 2: Curriculum Development}

Structure of VUKA Participants in the workgroups consistently provided positive feedback about the overall CHAMP structure. That is, they wanted to retain the multiple family groups and the overall format of each session. More specifically, they appreciated the opportunity for families and facilitators to share a meal, which has significant meaning in terms of bonding across cultures, promoting interaction and trust between participants. They also wanted to retain the structure of some joint activities between caregivers and youth, and some separate time with their respective age cohorts to meet in a safe space and discuss the topics. Parents wanted to be able to ask questions, brainstorm about parenting strategies, and share their own frustrations and stressors, without looking vulnerable to their children. The youth wanted a safe space to discuss adolescent issues (crushes, relationships, peer pressure, frustrations with parents, concerns about HIV), without fear of negative consequences, and to obtain peer support. Finally, participants appreciated the opportunity to come together as families to work on activities focused on session topics and to learn from each other.

Curriculum Format In the USA, CHAMP and CHAMP+ used written curricula, with structured activities. Session topics are brought up verbally by facilitators and all materials are primarily in written form. CHAMPSA (CHAMP for HIVnegative youth in South Africa) developed a cartoon-based curriculum based on stakeholder feedback that caregivers and youth would have tremendous difficulty discussing sexuality and puberty as such open communication would be atypical in this context. As described by Petersen et al. (2006), in South Africa, the use of cartoons provided a context for family communication of sensitive or difficult to discuss topics, such as sexuality or death, for which cultural norms do not always support discussions between parents and youth. Moreover, given the stigma of HIV/AIDS, discussions about HIVrelated loss and transmission were also deemed to be quite challenging. Thus, educators and artists translated the written curriculum of CHAMP into a cartoon-based story line for CHAMPSA. The premise was that participants could explore the topics through the cartoon characters, providing a safe space for family discussions. During the workshops for VUKA, participants thought this same strategy would be very helpful to them, and providers believed that the cartoons could help the project team to address literacy concerns in regard to curriculum content. Facilitators could read the dialog, but participants could follow along more easily with the pictures that expressed many of the emotions and story line by themselves.

Moreover, the use of the cartoons with a structured manual would be helpful for lay counselors with limited training, thereby promoting sustainability in many low resource settings. Although funding was not initially available for a cartoon-based curriculum, the study team was able to secure local foundation funding to develop one. The artistic and educational team that created the CHAMPSA story line and cartoons were available to continue the project for VUKA and joined future workshops.

Curriculum Content Table 1 presents the 10-session curriculum for CHAMP, CHAMPSA, and CHAMP+US. Many of the original topics were retained for each adaptation, but there were some critical differences. All iterations included sessions on communication within families, HIV knowledge, parental supervision and monitoring, puberty, social support, and navigating risky situations. CHAMP+US added content specific to living as an adolescent with HIV, such as medication adherence, feelings about HIV, disclosure, and stigma. A session on HIV stigma was also used in CHAMPSA, as was a session on surviving loss and bereavement, given the high prevalence and everyday presence of HIV and related loss in South Africa. As noted, participants reviewed all three curricula. Many of the CHAMP and CHAMPSA sessions were retained. However, given that $\mathrm{HIV}+$ youth were the target population, the additional sessions on HIV, adherence, and disclosure from CHAMP+US were included. Consultant participants felt that the topics in CHAMP+ for the most part reflected their needs. That said, there were a few areas in which changes were needed, even if overall topic names were the same. The curriculum for VUKA included the following ten sessions: 
Table 1 Comparison of CHAMP program sessions

\begin{tabular}{|c|c|c|}
\hline CHAMP & CHAMP+ & CHAMPSA \\
\hline Working together to keep our kids safe! & $\begin{array}{l}\text { Getting to know the CHAMP+ family program: } \\
\text { Working together to keep our kids safe!! }\end{array}$ & $\begin{array}{l}\text { Parents' and children's rights and } \\
\text { responsibilities }\end{array}$ \\
\hline Talking and listening to each other & How we feel about HIV & Parenting styles \\
\hline Keeping track of kids part 1 & $\begin{array}{l}\text { Talking and listening to each other: } \\
\text { HIV and disclosure }\end{array}$ & Talking and listening \\
\hline Keeping track of kids part 2 & $\begin{array}{l}\text { Talking and listening to each other: } \\
\text { HIV and stigma }\end{array}$ & Puberty \\
\hline Who can help us raise our children & HIV education & Hard to tell stuff \\
\hline Rules keep kids safe & HIV medication maintenance & Identifying risk \\
\hline Growing up: talking about puberty & Growing up and puberty & What is HIV/AIDS? \\
\hline What we need to know about HIV/AIDS & $\begin{array}{l}\text { Talking about peer pressure and sexual possibility } \\
\text { situations }\end{array}$ & Dealing with stigma \\
\hline $\begin{array}{l}\text { Growing up: preparing kids for } \\
\text { adolescence }\end{array}$ & Keeping track of kids and family communication & Surviving loss and bereavement \\
\hline \multirow[t]{2}{*}{ Celebration } & $\begin{array}{l}\text { Rules to keep kids safe } \\
\text { Who can help us raise our children? } \\
\text { Social support and HIV }\end{array}$ & Support networks \\
\hline & Where we have been and where we are going & \\
\hline
\end{tabular}

- Session 1: surviving loss and bereavement

- Session 2: what is HIV?

- Session 3: ART and adherence

- Session 4: identity, acceptance, and coping

- Session 5: disclosure

- Session 6: communication

- Session 7: puberty and adolescent development

- Session 8: negotiating sexual possibility situations and peer pressure

- Session 9: dealing with stigma

- Session 10: family support networks

VUKA Manual and Story Line To facilitate the sessions, the cartoon curriculum follows the story of a 12-year-old boy, Themba, who has just lost his mother to AIDS and has moved to a new community with his aunt and uncle (the VUKA family), along with his baby sister. His aunt has both children tested for HIV, given that their parents died of AIDS, and Themba soon finds out he has HIV. The story explores how normal adolescent issues are experienced by the VUKA family in the context of HIV infection. A structured facilitator manual was developed to allow easy implementation of the VUKA intervention by lay counselors already working in clinics. For each session, the manual facilitates review of part of the story line in the cartoons and provides activities, discussion questions, probes, and tips for engaging participants in each topic/session.

Below is a more detailed description of each session and the specific feedback from workgroups, related to the choices made about session content and the story.
Session 1 Loss and bereavement. In session 1, the participants are introduced to Themba, his sister, and their new family. Although his aunt is very welcoming, her husband is not. Themba must sleep on the couch and looks through his memory box feeling sad about all he has left behind. In the adaptation phase of CHAMP+US, HIV+ youth and caregivers had insisted that the first session allow them to discuss their personal stories of how HIV came into their lives. Even though it was counterintuitive to many of the clinician investigators to discuss the most difficult topic in the first session in which strangers meet, families believed it was critical for building trust and enabling exploration of other topics.

The South African caregivers and youth took this one step further to talk about loss and grief. In South Africa, the toll of HIV/AIDS has been staggering with almost no family untouched, particularly in Black communities. By definition, children growing up with HIV have at least one parent with HIV, and at the time of the study, many had also lost a parent to HIV-related death. Caregivers who mostly consisted of grandmothers ("Gogos"), aunts, and some HIV+ parents felt very strongly that the first session had to address themes of loss and bereavement as this set the tone for all other communications. Caregivers had difficulty with this topic, however, and wanted this session to help them more effectively support children who had lost their parents as well as address concerns about their future. Providers shared 
concerns that many of the children in the clinic were not given the space to mourn the loss of their parents - in part because the children felt like a burden to their new families and also because of the stigma of AIDS. Providers and caregivers also believed that many children had unresolved anger at parents for giving them the virus and needed their own space to talk about this. Youth expressed fear about the future, not only because of the potential for or reality of parental death, but also because new caregivers were often elderly.

In South Africa, memory boxes are frequently used to help children maintain the memory of people who have died. These boxes include mementos, pictures, letters, and other small objects from people who have passed on. All stakeholders believed the story line should utilize memory boxes in some way to encourage children and caregivers to create them or generate discussion. See Fig. 2.

Sessions 2-3. HIV, ART, and adherence. These sessions provide information about HIV, how the virus attacks the body and affects the immune system, how ART works to contain the virus, and reasons that adherence is so critical to treatment. Much of the information from CHAMP+US was retained. Although providers reported that youth participants had received significant education about HIV throughout their lives, they believed caregivers, who often did not speak English (the dominant language of most physicians), did not receive the same level of education. They reported that many caregivers had concerns about Western medicine and the toxicity of ART medications and had strong beliefs in traditional healing strategies, requiring more culturally appropriate materials. South African participants believed that there was a need to educate parents and children through mutual discussions, using images and metaphors utilized by South African providers and counselors. Thus, a metaphor of a castle was used to represent the body; castle guards represented the immune system to fight the germs and viruses that invade the body, and the HIV virus itself was represented as enemy soldiers. Quizzes were used to debunk myths associated with HIV and AIDS. Although the
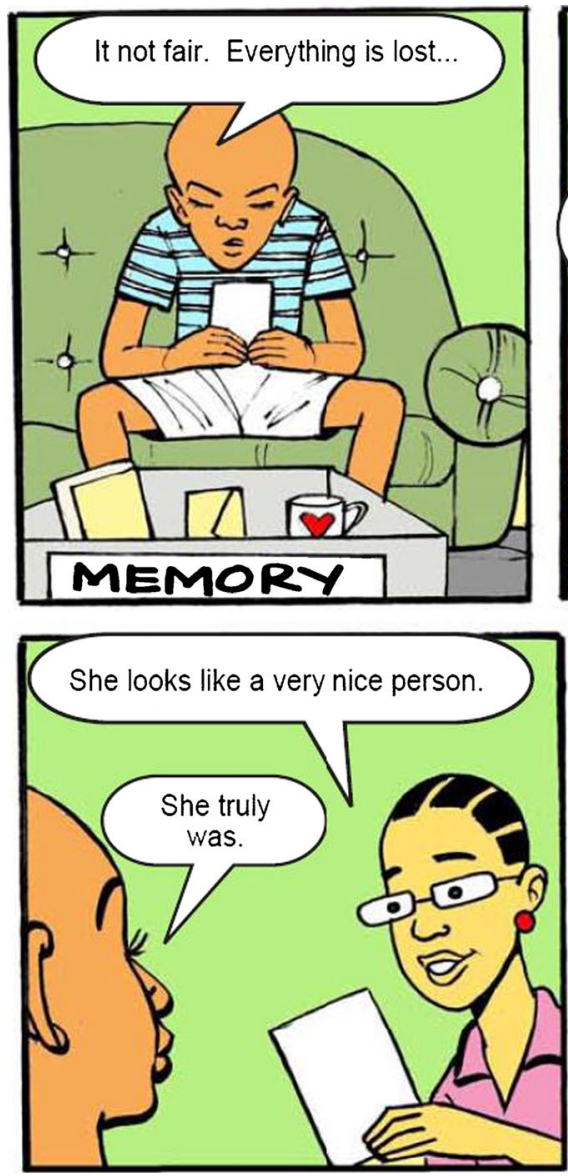

Fig. 2 Loss and bereavement
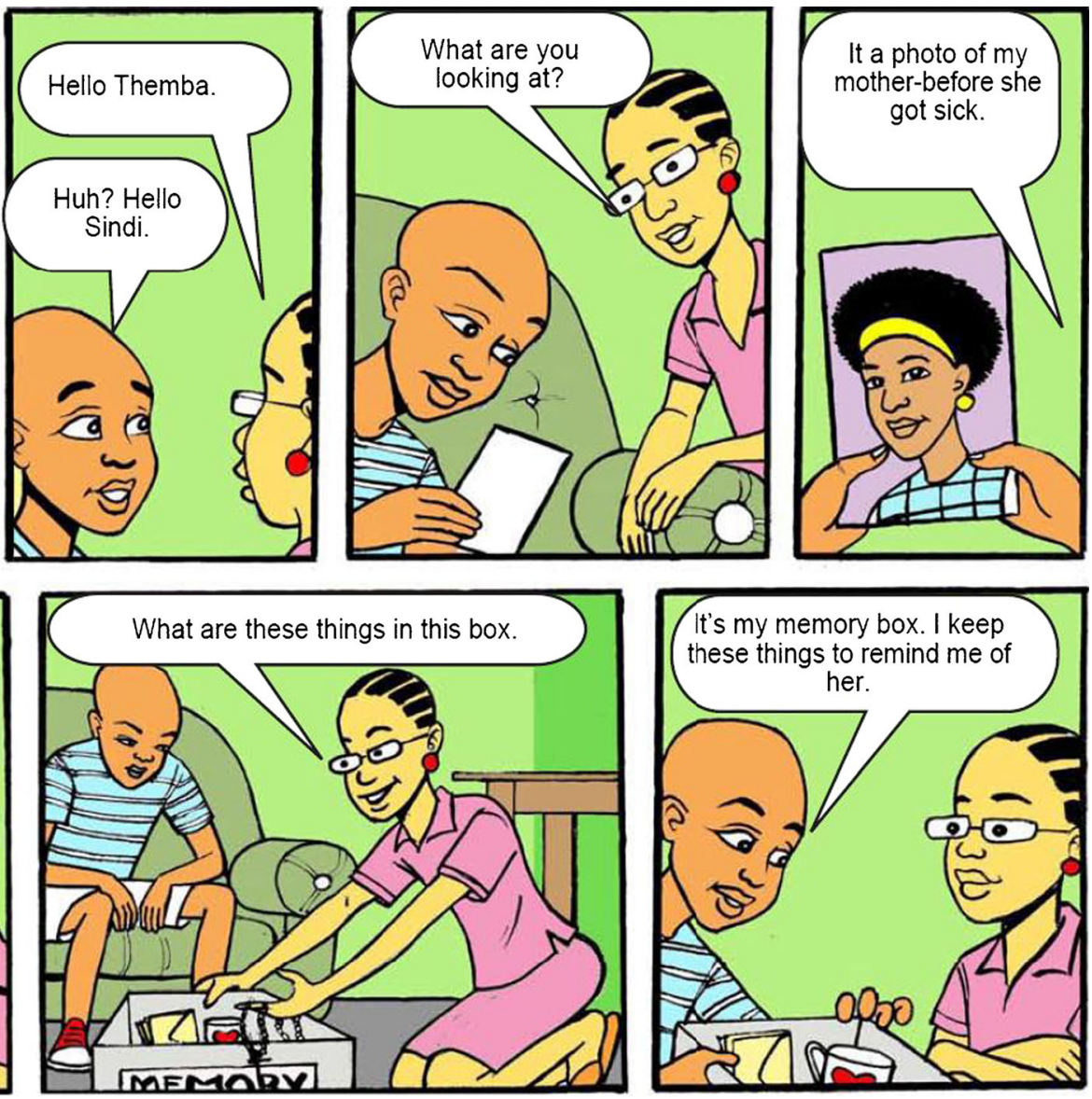
curriculum addresses stigma and misperceptions about ART, VUKA materials acknowledge families' option to use all types of care in promoting health while also stressing the importance of ART for HIV.

As in other countries, difficulty with ART adherence was a prominent theme raised in the workshops. Consumer participants and mental health and medical providers believed that adherence discussions needed to normalize nonadherence and promote discussions of common barriers and strategies to overcome them, including linking adherence to future orientation and longevity. Providers believed discussions should focus on the need to maintain health through the use of medications and move families away from curative discussions that might lead to nonadherence when patients felt or looked better. They also believed caregivers needed to be engaged in their roles as treatment supporters for their children and that the groups could brainstorm about useful strategies in the stressful lives of families (e.g., pill boxes, reminders, use of other HIV+ family members or treatment buddies). See Fig. 3.

Session 4 Identity, acceptance, and coping. Session 4 focuses on coping strategies for dealing with HIV and adolescent identity development. While CHAMP+US included a session on coping and problem solving, the focus on identity development was a new focus in VUKA. From the formative qualitative research (Petersen et al. 2010), it was clear that many youth struggled to accept their HIV status and had concerns about their identity. They wanted to be normal teenagers, but felt that they were different. In some cases, caregivers and providers reported youth denial about their HIV status and that the youth often refused to discuss their HIV and sexual behaviors. Youth also talked about having a spoiled identity and that caregivers and service providers treated them as having special needs, which did not help them to feel normal. All participants thought not only that the curriculum should help youth have an identity beyond HIV, but also that the session should focus on the strengths these youth had acquired as a result of growing up with HIV. Thus, the story line explores Themba's feelings about his HIV and identity and presents alternative identities to being a child with HIV or an orphan, such as being a best friend to another boy. See Fig. 4.
Session 5 Disclosure. As all youth in VUKA need to know their diagnosis to participate in the intervention, session 5 focuses on disclosure to peers and other family members. The goals of this session are to help participants think about the process of disclosure, anticipate and prepare for diverse responses by others, and consider how to evaluate who is safe or appropriate to disclose to, and the best timing and strategies for disclosure. This session was retained from CHAMP+US, although the cartoon adds the issue of disclosure to a girlfriend, promoting discussion about partner disclosure. The session also reviews how to help PHIV+ youth and their parents explore the youth's reactions to and ability to cope with their own diagnosis. See Fig. 5.

Session 6 Communication. This session was retained from CHAMP, CHAMPSA, and CHAMP+US. The goal is to help parents and youth communicate more effectively with each other and to help youth communicate more effectively with peers in preparation for sessions 7 and 8 .

Session 7 Puberty and adolescent development. This session was also retained from CHAMP, CHAMPSA, and $\mathrm{CHAMP}+\mathrm{US}$. The facilitators provide education about normative adolescent development, including puberty and the physical and emotional challenges of this stage. The session also focuses on adolescents' need to begin separation from caregivers and to obtain social support from peers.

Session 8 Negotiating sexual possibility situations and peer pressure. This session retains the goals of the original CHAMP and CHAMP+US programs. It focuses on how to handle negative peer pressure around sexual and substance use risk behaviors and develop strategies for negotiating healthy relationships.

Sessions 9

and $10 \quad$ Stigma and discrimination and building support.

Session 9 focuses on ways to cope with potential stigma and negative treatment by peers and family. Although stigma is universal, the massive scope of the HIV epidemic in South Africa, its concentration in Black South African populations already discriminated against during Apartheid, and the late arrival of treatment have likely exacerbated stigma and discrimination of people living with HIV in this country. This stigma often results in failure to get tested early and non-adherence to treatment appointments and medications. Nonetheless, stakeholders believed that there was a significant need to address this issue in ways that promote resilience. Children and 

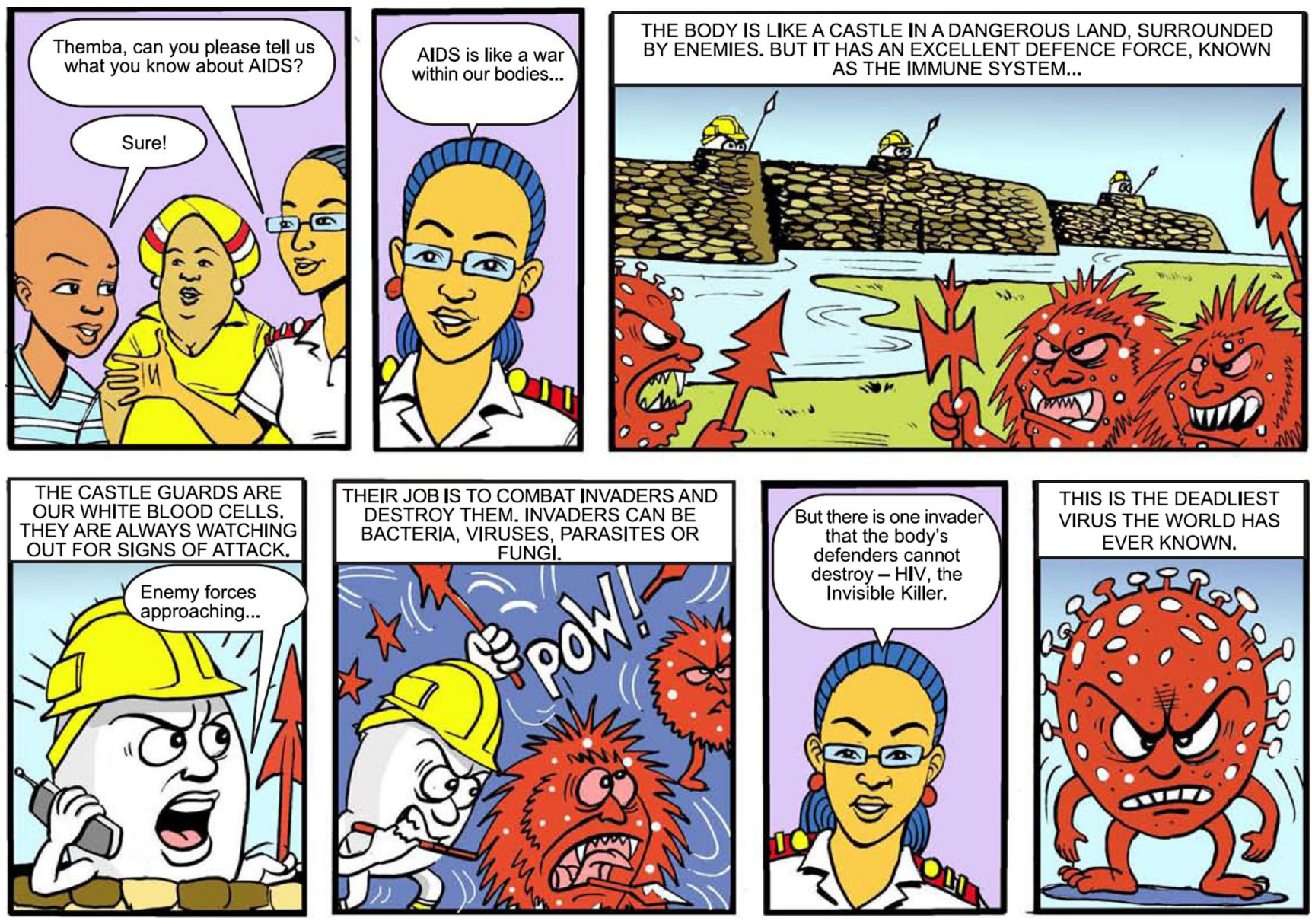

Fig. 3 HIV, ART, and adherence

families need to be empowered to cope with this adversity and to approach it from an ecological systemic perspective, creating a supportive family environment, as well as strengthening supportive networks with other HIV positive people, thereby building the necessary social capital to begin to address the issue of stigma at a community level, promoting movement toward greater acceptance of HIV positive people. Thus, families wanted the VUKA intervention to end with ways for both caregivers and adolescents to build social support, and thus, session 10 is focused on building community for families affected by HIV.
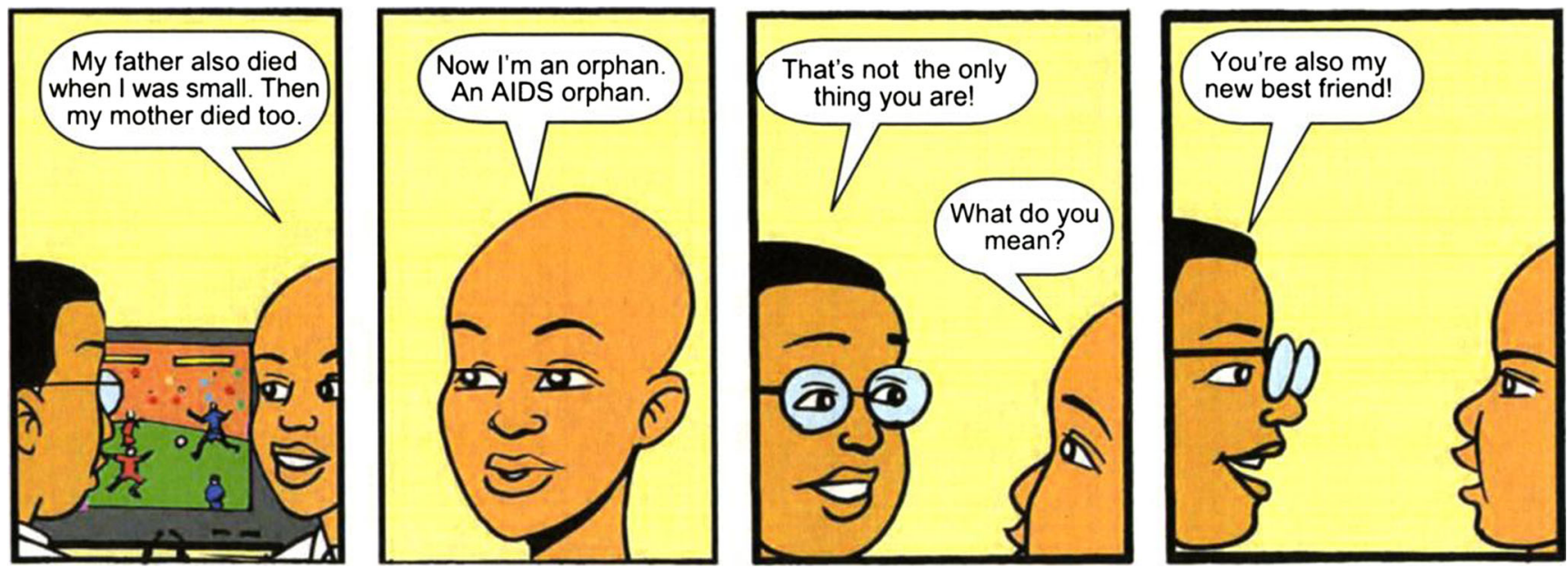

Fig. 4 Identity, acceptance, and coping 

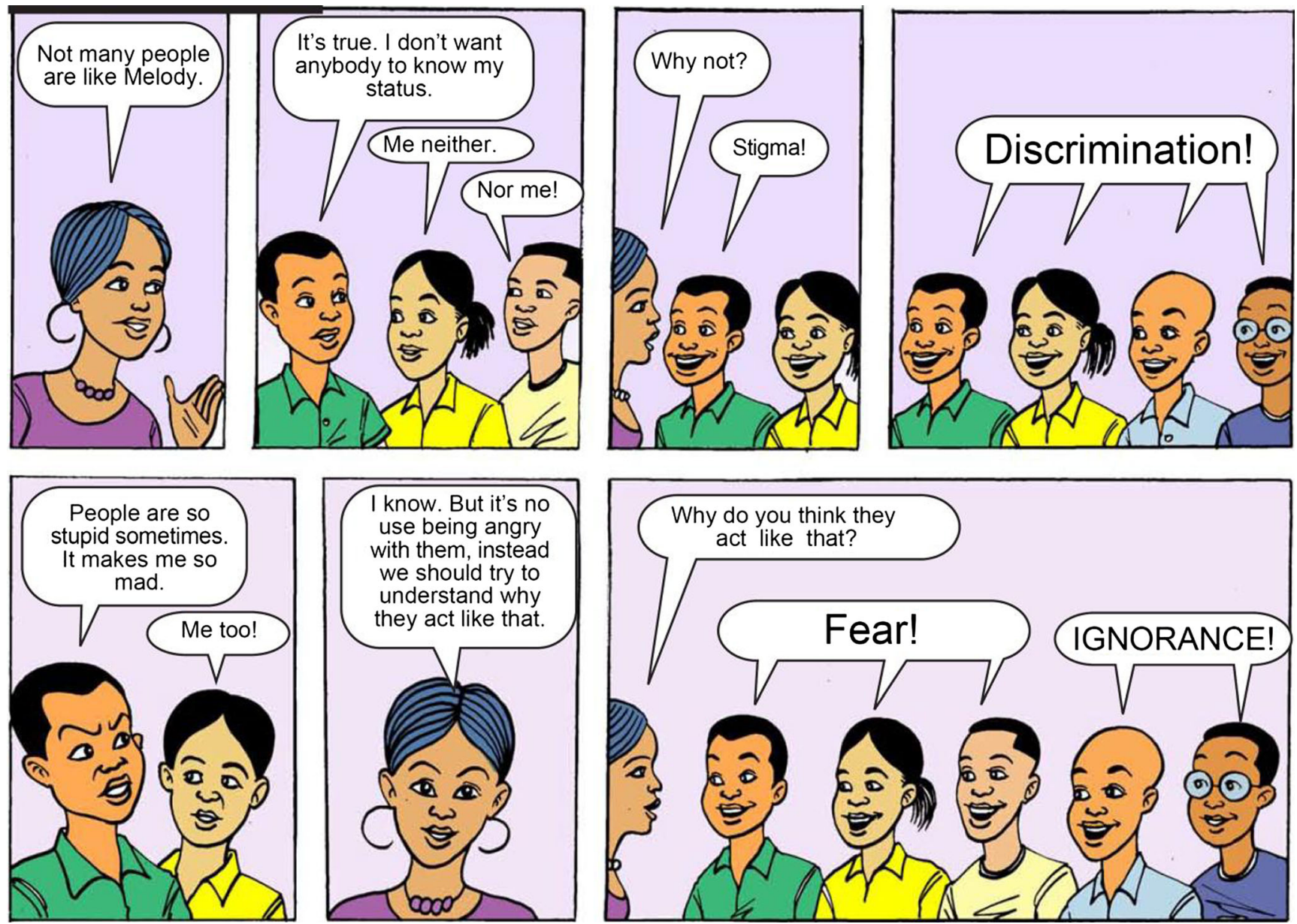

Fig. 5 Stigma and discrimination

\section{Discussion}

Given that millions of children under the age of 15 are living with HIV in sub-Saharan Africa and that ART is more accessible and available (UNAIDS 2012), a staggering number of adolescents and young adults will need evidence-based interventions to promote the behavioral health needs necessary for ensuring healthy individual outcomes and reducing further HIV transmission. Studies from the USA and other countries indicate high rates of mental health and adherence problems, and challenges related to normative experimentation with sex and substance use among this population, suggesting the need for interventions that target multiple risk behaviors (Mellins \& Malee 2013). While there are numerous psychosocial clinical efforts to address the mental health and prevention needs of $\mathrm{HIV}+$ adolescents across the globe, to date, CHAMP+ is the only program we know of that is being tested for efficacy and scalability that focuses on behavioral outcomes, including mental health, adherence, and sexual risk reduction. Preliminary evidence of efficacy has been shown in pilot RCTs in three countries, USA, Argentina, and South Africa (VUKA)(Small et al. 2014), and we are currently in the second year of a large-scale clinical trial of VUKA in four public health clinics in KwaZulu-Natal, South Africa.

That said, there is a critical need for more evidence-based psychosocial programs for this population in settings around the world, particularly in sub-Saharan Africa. While existing models, such as CHAMP+ or VUKA, are a useful starting point, they must be developed or adapted for each context. Yet, this does not mean having to start from scratch or "reinvent the wheel" each time. This paper presents an in-depth discussion of how VUKA investigators went about adapting CHAMP for the South Africa context and offers insight into the adaptation process across contexts.

The process of adapting and developing the VUKA intervention highlights the importance of CBPR. While many of the sessions from CHAMP+ remained relevant for HIV+ adolescents and caregivers in South Africa, if the existing intervention had been implemented without modification, we would have failed to address several significant issues in the lives of the target population. Stakeholders in South Africa unanimously endorsed the use of a cartoon-based curriculum as essential for overcoming literacy issues and introducing difficult or taboo topics. This was never considered in the 
USA for CHAMP or CHAMP+. Stakeholder interviews and workshops also revealed the importance of including a session on identity development for adolescents living with HIV, incorporating fears about the future into the session on loss and bereavement, and acknowledging/addressing the role of traditional healing in treatment beliefs. The story line was driven by consumer feedback, which allowed us to create characters that were recognizable to participants and to use familiar places, people, and ideas, including the metaphor of a castle in explaining HIV and how it affects one's body.

Echoing calls for task-shifting and the use of lay counselors in mental health care in South Africa (Petersen et al. 2012), stakeholders stressed the importance of developing a structured, manualized intervention for lay counselors in the clinics who may have limited training and supervision, which led to the development of a more structured facilitator's manual than had been used in CHAMP and CHAMP+. The use of lay counselors to deliver a manualized program in CHAMPSA and more recently in the VUKA pilot and current RCT field trials in public health facilities holds promise for greater uptake.

The adaptation process described here is easily replicable in multiple settings, and the lessons learned are likely applicable, as well. In addition to the importance of consumer and provider stakeholders described above, their involvement in the adaptation process increased their investment in the resulting intervention and built a sense of trust and partnership between them and the investigators. This was key to the successful implementation of VUKA and continuing communication and feedback about the program. Our experience also highlighted the need to be prepared to respond to the stakeholder feedback, even when that involves a change of plans or locating additional resources, as illustrated by our need to raise additional funds to develop the cartoon-based curriculum that participants and providers felt would be most beneficial.

This successful adaptation process required skills not typically taught in academic settings, nor always valued, but that are key for sustainability, including communication, flexibility, patience, true partnership in decision making and study design, and respect for differences across cultures and disciplines, and between researchers, providers, and consumers, as well as typically unfunded mandates, such as socializing and relationship building (McKay et al. 2007b; Mellins 2012). In sum, this paper lays out a process by which diverse groups of stakeholders were brought together and supported to use existing evidence and program components to support an emerging population of vulnerable youth in contexts of scarce resources. The use of CBPR methods facilitated the integration of consumer and provider input with existing and emerging science and this approach could have wide applications for youth and their families struggling with a range of serious health threats.
Acknowledgments This research was supported by grants from the National Institute of Nursing Research (NINR grant \#. R21NR10474; PI: Claude Ann Mellins, Ph.D.), the National Institute of Child Health and Development (NICHD grant \# R01 HD074052; PI Mary McKay, PhD), and the MTCT-Plus Initiative at ICAP-Columbia University, as well as by grants from the Victor Daitz Foundation and the Waldo Foundation. The MTCT-Plus Initiative was supported through funding provided by the Bill \& Melinda Gates Foundation, the William and Flora Hewlett Foundation, the Robert Wood Johnson Foundation, the Henry J. Kaiser Family Foundation, the John D. and Catherine T. MacArthur Foundation, the David and Lucile Packard Foundation, the Rockefeller Foundation, and the Starr Foundation. The research was also supported by a center grant from the National Institute of Mental Health to the HIV Center for Clinical and Behavioral Studies at the New York State Psychiatric Institute and Columbia University (P30-MH43520; Principal Investigator: Robert Remien). The authors would also like to acknowledge the significant time and effort and guidance of all of the participants in this project, including the tremendous support of the young people living with HIV and their families.

\section{References}

Abrams, E. J., Weedon, J., Bertolli, J., Bornschlegel, K., Cervia, J., Mendez, H., \& Thomas, P. (2001). Aging cohort of perinatally human immunodeficiency virus-infected children in New York City. The Pediatric Infectious Disease Journal, 20(5), 511-517.

Bauermeister, J. A., Elkington, K. S., Robbins, R. N., Kang, E., \& Mellins, C. A. (2012). A prospective study of the onset of sexual behavior and sexual risk in youth perinatally infected with HIV. Journal of Sex Research, 49(5), 413-422.

Bell, C. C., Bhana, A., Petersen, I., McKay, M. M., Gibbons, R., Bannon, W., \& Amatya, A. (2008). Building protective factors to offset sexually risky behaviors among black youths: a randomized control trial. Journal of the National Medical Association, 100(8), 936.

Betancourt, T. S., Meyers-Ohki, S. E., Charrow, A., \& Hansen, N. (2013). Annual research review: mental health and resilience in HIV/AIDSaffected children - a review of the literature and recommendations for future research. Journal of Child Psychology and Psychiatry, 54(4), 423-444.

Bhana, A., McKay, M. M., Mellins, C., Petersen, I., \& Bell, C. (2010). Family-based HIV prevention and intervention services for youth living in poverty-affected contexts: the CHAMP model of collaborative, evidence-informed programme development. Journal of the International AIDS Society, 13(Suppl 2), S8.

Bhana, A., Mellins, C. A., Petersen, I., Alicea, S., Myeza, N., Holst, H., \& McKay, M. (2014). The VUKA family program: piloting a familybased psychosocial intervention to promote health and mental health among HIV infected early adolescents in South Africa. AIDS Care, 26(1), 1-11.

Bomba, M., Nacinovich, R., Oggiano, S., Cassani, M., Baushi, L., Bertulli, C., \& Badolato, R. (2010). Poor health-related quality of life and abnormal psychosocial adjustment in Italian children with perinatal HIV infection receiving highly active antiretroviral treatment. AIDS Care, 22(7), 858-865.

Boyd-Franklin, N., del Aleman, J. C., Jean-Gilles, M. M., \& Lewis, S. Y. (1995). Cultural sensitivity and competence: African-American, Latino, and Haitian families with HIV/AIDS. In N. Boyd-Franklin, G. L. Steiner, \& M. G. Boland (Eds.), Children, families and HIV/ AIDS: psychosocial and therapeutic issues (pp. 53-77). New York: Guilford Press.

Brouwers, P., Belman, A. L., \& Epstein, L. G. (1991). Central nervous system involvement: manifestations and evaluation. In W. C. Pizzo (Ed.), Pediatric AIDS: the challenge of HIV infection in Infants, 
children and adolescents (pp. 318-335). Baltimore: Williams and Witkin.

Centers for Disease Control and Prevention. (2013). Pediatric HIV surveillance. Retrieved from http://www.cdc.gov/hiv/pdf/statistics surveillance_Pediatric.pdf.

Chase, C., Ware, J., Hittleman, J., et al. (2000). Early cognitive and motor development among infants born to women infected by human immunodeficiency virus. Pediatrics, 106(2), e25.

Cluver, L. D., Gardner, F., \& Operario, D. (2008). Effects of stigma on the mental health of adolescents orphaned by AIDS. Journal of Adolescent Health, 42(4), 410-417.

Cluver, L., Operario, D., \& Gardner, F. (2011). A family disease: children orphaned by AIDS and living with HIV+ caregivers. In H. E. Fitzgerald, K. Puura, M. Tomlinson, \& P. Campbell (Eds.), International perspectives on children and mental health (pp. 6588). California: ABC-CLIO, LLC.

Connor, E. M., Sperling, R. S., Gelber, R., Kiselev, P., Scott, G., O’Sullivan, M. J., \& Balsley, J. (1994). Reduction of maternalinfant transmission of human immunodeficiency virus type 1 with zidovudine treatment. New England Journal of Medicine, 331(18), $1173-1180$.

Coovadia, H. M., Brown, E. R., Fowler, M. G., Chipato, T., Moodley, D., Manji, K., \& Maldonado, Y. (2012). Efficacy and safety of an extended nevirapine regimen in infant children of breastfeeding mothers with HIV-1 infection for prevention of postnatal HIV-1 transmission (HPTN 046): a randomised, double-blind, placebocontrolled trial. The Lancet, 379(9812), 221-228. doi:10.1016/ S0140-6736(11)61653-X.

Corby, N. H. (1997). Priority-population assessment for HIV prevention program development. In R. J. Wolitski (Ed.), Community HIV prevention: The Long Beach AIDS community demonstration project (pp. 125-134). Long Beach: University Press.

de Martino, M., Tovo, P. A., Balducci, M., Galli, L., Gabiano, C., Rezza, G., \& Italian Register for HIV Infection in Children. (2000). Reduction in mortality with availability of antiretroviral therapy for children with perinatal HIV-1 infection. JAMA, 284(2), 190-197.

Department of Health and Human Services. (2014). Recommendations for use of antiretroviral drugs in pregnant HIV-1-infected women for maternal health and interventions to reduce perinatal HIV transmission in the United States. Retrieved from http://aidsinfo.nih.gov/ contentfiles/lvguidelines/PerinatalGL.pdf.

Domek, G. J. (2006). Social consequences of antiretroviral therapy: preparing for the unexpected futures of HIV-positive children. The Lancet, 367(9519), 1367-1369.

Domek, G. J. (2009). Facing adolescence and adulthood: the importance of mental health care in the global pediatric AIDS epidemic. Journal of Developmental \& Behavioral Pediatrics, 30(2), 147-150.

Ferrand, R. A., Luethy, R., Bwakura, F., Mujuru, H., Miller, R. F., \& Corbett, E. L. (2007). HIV infection presenting in older children and adolescents: a case series from Harare, Zimbabwe. Clinical Infectious Diseases, 44(6), 874-878.

Gadow, K. D., Angelidou, K., Chernoff, M., Williams, P. L., Heston, J., Hodge, J., \& Nachman, S. (2012). Longitudinal study of emerging mental health concerns in youth perinatally infected with HIV and peer comparisons. Journal of Developmental and Behavioral Pediatrics, 33(6), 456-468.

Hamburg, B. A. (1990). Life skills training: preventive interventions for young adolescents. Carnegie council on adolescent development: working papers. New York: Carnegie Corporation.

Havens, J. F., \& Mellins, C. A. (2008). Psychiatric aspects of HIV/AIDS in childhood and adolescence. In M. Rutter \& E. Taylor (Eds.), Child and adolescent psychiatry (5th edn., pp. 828-841). Oxford, UK.

Kang, E., Mellins, C. A., Ng, W. Y. K., Robinson, L. G., \& Abrams, E. J. (2008). Standing between two worlds in Harlem: a developmental psychopathology perspective of perinatally acquired human immunodeficiency virus and adolescence. Journal of Applied Developmental Psychology, 29(3), 227-237.

King, E., De Silva, M., Stein, A., \& Patel, V. (2009). Interventions for improving the psychosocial well-being of children affected by HIV and AIDS. Cochrane Database of Systematic Reviews, 3.

Malee, K. M., Tassiopoulos, K., Huo, Y., Siberry, G., Williams, P. L., Hazra, R., \& Pediatric HIV/AIDS Cohort Study Team. (2011). Mental health functioning among children and adolescents with perinatal HIV infection and perinatal HIV exposure. AIDS Care, 23(12), 1533-1544.

McKay, M., \& Paikoff, R. (2007). Community collaborative partnerships: the foundation for HIV prevention research efforts. New York: Haworth Press.

McKay, M., Block, M., Mellins, C., Traube, D., Brackis-Cott, E., Miranda, C., Petterson, J., \& Abrams, E. (2007a). Adapting a family-based HIV prevention program for HIV-infected preadolescents and their families: youth, families and health care providers coming together to address complex needs. In M. McKay \& R. Paikoff (Eds.), Community collaborative partnerships: the foundation for HIV prevention research efforts. New York: Haworth Press.

McKay, M. M., Hibbert, R., Lawrence, R., Miranda, A., Paikoff, R., Bell, C. C., \& Bannon, W. M., Jr. (2007b). Creating mechanisms for meaningful collaboration between members of urban communities and university-based HIV prevention researchers. Social Work in Mental Health, 5(1-2), 147-168.

McKay, M. M., Alicea, S., Elwyn, L., McClaim, Z. B. R., Parker, G., Small, L., \& Mellins, C. A. (2014). Theory-driven programs capable of addressing poverty-impacted children's health, mental health and prevention needs: CHAMP and CHAMP+. Journal of Clinical Child and Adolescent Psychology, 43, 428-441.

Mellins C. A. (2012, July). The VUKA family project. Invited presentation at the XVIVth International AIDS Conference, Washington, DC.

Mellins, C. A., \& Malee, K. M. (2013). Understanding the mental health of youth living with perinatal HIV infection: lessons learned and current challenges. Journal of the International AIDS Society, 16(1), 18593.

Mellins, C. A., Tassiopoulos, K., Malee, K., Moscicki, A. B., Patton, D., Smith, R., III, \& for the Pediatric HIV-AIDS Cohort Study. (2011). Behavioral health risks in perinatally HIV-exposed youth: cooccurrence of sexual and drug use behavior, mental health problems, and nonadherence to antiretroviral treatment. AIDS Patient Care and STDs, 25(7), 413-422.

Mellins, C. A., Elkington, K. S., Leu, C. S., Santamaria, E. K., Dolezal, C., Wiznia, A., \& Abrams, E. J. (2012). Prevalence and change in psychiatric disorders among perinatally HIV-infected and HIVexposed youth. AIDS Care, 24(8), 953-962.

Menon, A., Glazebrook, C., Campain, N., \& Ngoma, M. (2007). Mental health and disclosure of HIV status in Zambian adolescents with HIV infection: implications for peer-support programs. JAIDS Journal of Acquired Immune Deficiency Syndromes, 46(3), 349-354.

Meyers, T., Moultrie, H., Naidoo, K., Cotton, M., Eley, B., \& Sherman, G. (2007). Challenges to pediatric HIV care and treatment in South Africa. Journal of Infectious Diseases, 196(Supplement 3), S474 S481.

New York City Department of Health. (2012). Pediatric HIV/AIDS surveillance update NYC. Retrieved from www.nyc.gov/html/doh/ downloads/pdf/dires/ped-annual-rpt-2012.pdf.

Nyblade, L., Stangl, A., Weiss, E., \& Ashburn, K. (2009). Combating HIV stigma in health care settings: what works? Journal of the International AIDS Society, 12(1), 15.

Nyblade, L., Singh, S., Ashburn, K., Brady, L., \& Olenja, J. (2011). "Once I begin to participate, people will run away from me": understanding stigma as a barrier to HIV vaccine research participation in Kenya. Vaccine, 29(48), 8924-8928.

Petersen, I., Mason, A., Bhana, A., Bell, C. C., \& Mckay, M. (2006). Mediating social representations using a cartoon narrative in the 
context of HIV/AIDS: the AmaQhawe Family Project in South Africa. Journal of Health Psychology, 11(2), 197-208.

Petersen, I., Bhana, A., Myeza, N., Alicea, S., John, S., Holst, H., \& Mellins, C. (2010). Psychosocial challenges and protective influences for socio-emotional coping of HIV+ adolescents in South Africa: a qualitative investigation. AIDS Care, 22(8), 970-978.

Petersen, I., Lund, C., Bhana, A., \& Flisher, A. J. (2012). A task shifting approach to primary mental health care for adults in South Africa: human resource requirements and costs for rural settings. Health Policy and Planning, 27(1), 42-51.

Puthanakit, T., Ananworanich, J., Vonthanak, S., Kosalaraksa, P., Hansudewechakul, R., van der Lugt, J., \& PREDICT Study Group. (2013). Cognitive function and neurodevelopmental outcomes in HIVinfected children older than 1 year of age randomized to early versus deferred antiretroviral therapy: the PREDICT neurodevelopmental study. The Pediatric Infectious Disease Journal, 32(5), 501.

Republic of South Africa. (2010). Country progress report on the declaration of commitment in HIV/AIDS. Retrieved from http://data. unaids.org/pub/Report/2010/southafrica_2010_country_progress_ report_en.pdf.

Small, L., Mercado, M., Gopalan, P., Pardo, G., Mellins, C. A., \& McKay, M. M. (2014). Enhancing the emotional well-being of perinatally HIV-infected youth across global contexts. Global Social Welfare, l(1), 25-35.

Smith, R., \& Wilkins, M. (2014). Perinatally acquired HIV infection: Long-term neuropsychological consequences and challenges ahead. Child Neuropsychology, 1-35.

Sohn, A. H., \& Hazra, R. (2013). The changing epidemiology of the global paediatric HIV epidemic: keeping track of perinatally HIVinfected adolescents. Journal of the International AIDS Society, 16(1), 18555

Tassiopoulos, K., Moscicki, A. B., Mellins, C., Kacanek, D., Malee, K., Allison, S., \& Seage, G. R. (2013). Sexual risk behavior among youth with perinatal HIV infection in the United States: predictors and implications for intervention development. Clinical Infectious Diseases, 56(2), 283-290.
UNAIDS. (2010). Report on the global AIDS epidemic. Retrieved from http://www.unaids.org/globalreport/Global report.htm.

UNAIDS. (2012). Report on the global AIDS epidemic. Retrieved from http://www.unaids.org/globalreport/Global_report.htm.

UNAIDS, UNICEF, \& USAID. (2004). Children on the brink 2004: a joint report of new orphan estimates and a framework for action. New York: UNICEF.

UNICEF. (2011). Opportunity in crisis: preventing HIV from early adolescence to young adulthood. New York: UNICEF.

Van Dyke, R. B., Patel, K., Siberry, G. K., Burchett, S. K., Spector, S. A., Chernoff, M. C., \& Seage, G. R., III. (2011). Antiretroviral treatment of US children with perinatally-acquired HIV infection: temporal changes in therapy between 1991 and 2009 and predictors of immunologic and virologic outcomes. Journal of Acquired Immune Deficiency Syndromes, 57(2), 165.

Van Dyke, R. B., Patel, K., Kagen, R. M., Traite, S., Meyer, W. A., Tassiopoulos, K., \& Hazra, R., for the Pediatric HIV-AIDS Cohort Study. (2014, March). Prevalence and predictors of HIV drug resistance among US children and youth with perinatal HIV. Poster presented at the Conference on Retroviruses and Opportunistic Infections, Boston, MA.

Wainberg, M. L., McKinnon, K., Mattos, P. E., Pinto, D., Mann, C. G., de Oliveira, C. S. D. S., \& Cournos, F. (2007). A model for adapting evidence-based behavioral interventions to a new culture: HIV prevention for psychiatric patients in Rio de Janeiro, Brazil. AIDS and Behavior, 11(6), 872-883.

Wiener, L., \& Mellins, C. A. (2012). Psychosocial aspects of neurological impairment in children with AIDS. In H. E. Gendelman, I. P. Everall, H. S. Fox, I. Grant, S. Lipton, \& S. Swindells (Eds.), The neurology of AIDS (3rd ed., pp. 925-942). Oxford: Oxford University Press, Inc.

Williamson, J. (2005). Finding a way forward. In G. Foster, C. Levine, \& J. Williamson (Eds.), A generation at risk: the global impact of HIV/ AIDS on orphans and vulnerable children. Cambridge, UK: Cambridge University Press. 